\title{
Identification of Active Sites for Oxygen Reduction Reaction on Nitrogen- and Sulfur-Codoped Carbon Catalysts
}

\author{
Karl Markus Villemson, ${ }^{\dagger}$ Kätlin Kaare, ${ }^{\ddagger}$ Ragle Raudsepp, ${ }^{\ddagger}$ Tanel Käämbre, ${ }^{\S}$ Krišjānis Šmits,

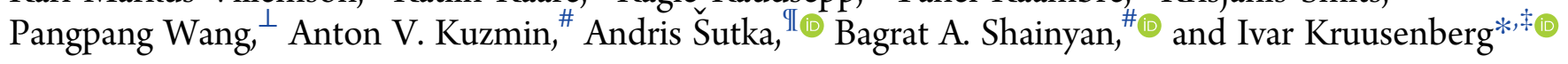 \\ ${ }^{\dagger}$ Institute of Chemistry, University of Tartu, Ravila 14a, 50411 Tartu, Estonia \\ ${ }^{\ddagger}$ National Institute of Chemical Physics and Biophysics, Akadeemia tee 23, 12618 Tallinn, Estonia \\ ${ }^{\S}$ Institute of Physics, University of Tartu, Wilhelm Ostwald Street 1, 50411 Tartu, Estonia \\ "Institute of Solid State Physics, University of Latvia, Kengaraga 8, 1063 Riga, Latvia \\ ${ }^{\perp}$ Nanomaterials Laboratory, Institute of Systems, Information Technologies and Nanotechnologies, 819-0388 Fukuoka, Japan \\ ${ }^{\#}$ Siberian Branch of Russian Academy of Sciences, A. E. Favorsky Irkutsk Institute of Chemistry, 1 Favorsky Street, 664033 Irkutsk, \\ Russian Federation \\ ${ }^{\mathbb{T}}$ Research Laboratory of Functional Materials Technologies, Faculty of Materials Science and Applied Chemistry, Riga Technical \\ University, P. Valdena 3/7, 1048 Riga, Latvia
}

ABSTRACT: Nitrogen- and sulfur-codoped carbon catalysts were prepared as electrocatalytic materials for the oxygen reduction reaction (ORR). Herein, we propose a novel and effective one-pot synthetic approach to prepare a NS-doped carbon catalyst by using the mixture of graphene oxide and multi-walled carbon nanotubes as a carbon support. Successful NS-doping of carbon and formation of the catalytically active sites were confirmed by X-ray photoelectron spectroscopy and with energy dispersion spectroscopy. The ORR activity of NS-codoped carbon was investigated by using a rotating disc electrode method. The NS-doped carbon shows superior ORR performance in alkaline media, and the electrocatalytic mechanism for the reduction of oxygen was well explained by density functional theory calculations of graphene sheets.

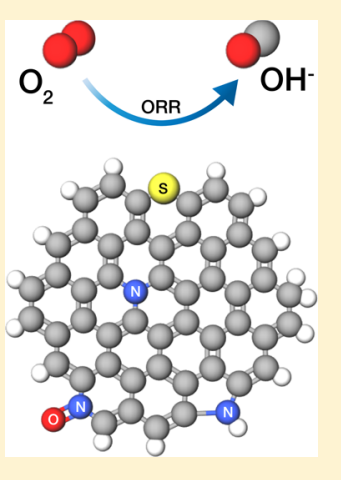

\section{INTRODUCTION}

One of the main obstacles to develop and commercialize energy conversing and storing systems such as fuel cells and metal-air batteries is the slow reaction kinetics of the oxygen reduction reaction (ORR). At present, Pt-based catalysts are mainly used in order to lower the activation energy and accelerate the ORR. In view of high cost and poor durability of Pt-based catalysts, it is estimated that almost half of the fuel cell cost comes from the noble metal catalyst. ${ }^{1,2}$ Starting from the 1960s, scientists have been trying to find the alternative to Pt-based catalysts in fuel cells. Many of these studies have demonstrated that metal-free carbon nanomaterials doped with heteroatoms are one of the promising materials because of their low cost, long-term stability, good endurance to fuel impurities, and prominent catalytic activity for the ORR. Carbon nanomaterials such as graphene, graphene oxide (GO), carbon nanotubes (CNTs), mesoporous carbon, and so forth serve as an excellent catalyst support because of their large specific area and superb electrical conductivity. Nevertheless, carbon materials alone are not active enough to catalyze ORR. One of the possibilities to increase their activity is to dope heteroatoms into the carbon network. Mainly, N, P, $\mathrm{S}$, and $\mathrm{B}$ are used as dopants because of their reasonable atomic size compared with the carbon atom. ${ }^{3-15}$ Because all of these dopants mentioned have different number of valence electrons compared to the carbon, they change electron-donor properties of the material and create active sites for oxygen adsorption. Because of the synergistic effect of codoping, it is shown to be more effective than doping with one heteroatom. $^{16,17}$ Zhang et al. and Qui et al. have both demonstrated increased activity in codoped N/S carbon materials compared with the solely doped $\mathrm{N}$ or $\mathrm{S}$ carbon framework. $^{18,19}$

As a result of doping, the atomic charge density and spin density are changed; charge redistribution facilitates the $\mathrm{O}_{2}$ chemisorption on the carbon material surface, weakens the $\mathrm{O}-$ $\mathrm{O}$ bonding, and as a result promotes the ORR process. ${ }^{20}$ Different carbon materials, such as ordered mesoporous carbon, $^{21}$ carbon dots, ${ }^{22}$ carbon nanofiber networks, ${ }^{23}$ graphene with carbon nanospheres, ${ }^{24}$ and mesoporous graphene $^{25}$ have been doped with nitrogen and sulfur in earlier works. Physical and chemical properties of graphene will make it the best possible candidate for catalyst formation. However, the problems related to restacking of graphene layers 
and agglomeration are making it difficult to use graphene as an electrocatalyst alone. ${ }^{26}$ Restacking causes decrease in the surface area, as it gets similar to graphite and this in turn also lowers the conductivity of the material. ${ }^{27}$ It has been reported that adding carbon black to graphene reduces the agglomeration of graphene sheets and, as a result, the electrochemical properties get better. ${ }^{28}$ Thereby, to avoid graphene restacking, it is utmost important to add some material to it, which could act as a spacer between the graphene layers and thus contribute to overall surface area and conductivity of the catalyst material. ${ }^{26}$ CNTs are widely used spacers for graphene. ${ }^{4,26,29}$ Adding CNTs to graphene has a positive effect on the electrochemical activity, as CNTs will create enough space for transport of reactants and also increase the electron transfer rate because CNTs act as circuits between graphene layers. ${ }^{29}$ Using spacers for graphene and doping with heteroatoms have both a synergistic effect that contributes to achieving better electrochemical activity for the ORR.

In this work, we demonstrate increased catalytic activity of facile, single-step codoped $\mathrm{N}$ and $\mathrm{S}$ carbon nanomaterials. $\mathrm{N}$ doping was chosen because of a large variety and availability of nitrogen-containing compounds as well as proven enhanced catalytic activity after nitrogen doping. S-doping has also shown to enhance ORR, but because the electronegativity of sulfur is rather similar to that of the carbon, its catalytic effect is determined by the change in spin density in carbon atoms. $^{30-33}$ On top of the electrochemical analysis and physical characterization, density functional theory (DFT) calculations of graphene sheets doped with sulfur atom and nitrogen atoms of three types (pyrrolic, pyridinic, and graphitic) were performed to support the experimental results and interpretations and to gain an insight into the structure and properties of the principal intermediates of ORR.

\section{EXPERIMENTAL SECTION}

2.1. Materials and Catalysts Preparation. The GO material used in this work was synthesized from graphite powder by a modified Hummers' method. ${ }^{3,34}$ Multi-walled CNTs (NanoLab) used in this work were acid-treated before their usage via a published procedure. ${ }^{35}$ Vulcan XC $72 \mathrm{R}$ was bought from Fuel Cell Store.

GO and MWCNTs were weighed and added into the vial so that the amount of GO would correspond to the weight of the nanotubes. To improve the material's properties, the mixture of GO and MWCNTs was doped in the presence of $\mathrm{N}$ and $\mathrm{S}$ precursor: $o$-methylisourea bisulfate (oMUS). oMUS was purchased from Sigma-Aldrich. To prepare the $\mathrm{N}$ - and Scodoped carbon catalyst, the first step was to ultrasonically blend GO and MWCNTs and surfactant polyvinylpyrrolidone in isopropanol (Honeywell).

Then, the $\mathrm{N}$ and $\mathrm{S}$ precursor with mass ratio 1 [1:1 MWCNT/reduced graphene oxide (rGO)]/5 (oMUS) was added, and dispersion was sonicated for $1 \mathrm{~h}$ to achieve a homogeneous mixture and dried in vacuum at $65{ }^{\circ} \mathrm{C}$. For heteroatom doping, the pyrolysis process is also needed, as the precursor decomposes at high temperatures and the doping also takes place simultaneously. The material was then collected into a quartz boat and pyrolyzed in a flowing nitrogen atmosphere at $800{ }^{\circ} \mathrm{C}$ for $2 \mathrm{~h}$. After that, the furnace was slowly cooled to room temperature and the products were collected and weighed. After blending, the catalysts were dried in vacuum at $75{ }^{\circ} \mathrm{C}$. The catalyst prepared in the presence of oMUS is designated as C/oMUS.
2.2. Physical Characterization. The X-ray photoelectron spectroscopy (XPS) measurements were performed using a Scienta SES100 hemispherical analyzer (operated at $200 \mathrm{eV}$ pass energy) and non-monochromated $\mathrm{Mg} \mathrm{K} \alpha$ incident exciting radiation from an XR-4 twin anode X-ray source (Thermo VG Scientific), with an overall spectral resolution of approximately $0.6 \mathrm{eV}$. The XPS sample was made by pressing the obtained flaky sample material into a metallic indium ingot.

A high-resolution elemental mapping analysis of the $\mathrm{C}$ / oMUS was conducted on spherical aberration-corrected scanning transmission electron microscopy (STEM, JEMARM200CF, JEOL, Japan) with energy dispersion spectroscopy (EDS) under an accelerating voltage of $200 \mathrm{kV}$. For the STEM-EDS observation, the suspension of the C/oMUS powder dispersed into ethanol was dropped onto a 200 mesh copper TEM grid containing a $20 \mathrm{~nm}$ thick amorphous carbon supporting film. Transmission electron microscopy images were obtained using Tecnai G2 F20 (FEI). A fast Fourier transform (FFT) analysis was made using a DigitalMicrograph (Gatan).

2.3. Electrode Preparation and Electrochemical Characterization. ORR polarization curves were measured using the rotating disk electrode (RDE) method. The experiments were undertaken using six different rotation rates $(\omega)$, from 4600 to $360 \mathrm{rpm}$. Pine AFMSRCE (Pine, USA) rotator and speed controlling unit were used for the RDE measurements. The software used for controlling the experiments was Nova 2.1.2 (Metrohm Autolab P.V., The Netherlands), and the potential was applied with a potentiostat/galvanostat Autolab PGSTAT 128N (Metrohm Autolab P.V., The Netherlands). All of the electrochemical tests were carried out by using three electrodes. The Pt foil was used as a counter electrode, saturated calomel electrode (SCE) as a reference electrode, and catalyst-coated glassy carbon (GC) electrode as a working electrode. All of the potentials in this work are referred to the SCE electrode. Electrochemical measurements were performed in $0.1 \mathrm{M} \mathrm{KOH}$ solution at room temperature $\left(23 \pm 1{ }^{\circ} \mathrm{C}\right)$. The solution was saturated with $\mathrm{O}_{2}$ (6.0) to study ORR, and for measuring background, the solution was saturated with $\mathrm{Ar}$ (5.0). A continuous flow of gases was maintained over the solution during the measurement.

GC electrodes were polished to a mirror finish with 1 and $0.3 \mu \mathrm{m}$ alumina slurries (Buehler) before the catalyst coating. To clean the electrodes from polishing debris, sonication in both 2-propanol and Milli-Q water for 5 min was undertaken. The C/oMUS catalyst suspension in isopropanol $\left(4 \mathrm{mg} \mathrm{mL}^{-1}\right)$ containing $0.25 \%$ Tokuyama $\mathrm{OH}^{-}$ionomer AS-4 (Tokuyama Corporation, Japan) was prepared for the modification of electrodes. The suspensions were then homogenized via sonication for $1 \mathrm{~h}$ prior to modifying the electrodes. After that, $20 \mu \mathrm{L}$ of the suspension was pipetted onto the GC surface in $5 \mu \mathrm{L}$ fractions to cover the surface of GC uniformly and was allowed to dry in an oven at $50{ }^{\circ} \mathrm{C}$ for $12 \mathrm{~h}$. The electrode loading used was $400 \mu \mathrm{g} \mathrm{cm}^{-2}$.

2.4. Theoretical Calculations. Theoretical calculations were performed at the DFT level using Becke's threeparameter exchange potential and Lee-Yang-Parr correlation functional. All calculations were performed with full geometry optimization using $6-31+\mathrm{G}(\mathrm{d})$ basis set or $6-311 \mathrm{G}(\mathrm{d})$ basis set for frequency calculations, utilizing Gaussian09 program suite $^{36}$ and visualized with ChemCraft program. ${ }^{37}$ Because the process under investigation occurs in oxidative conditions, 

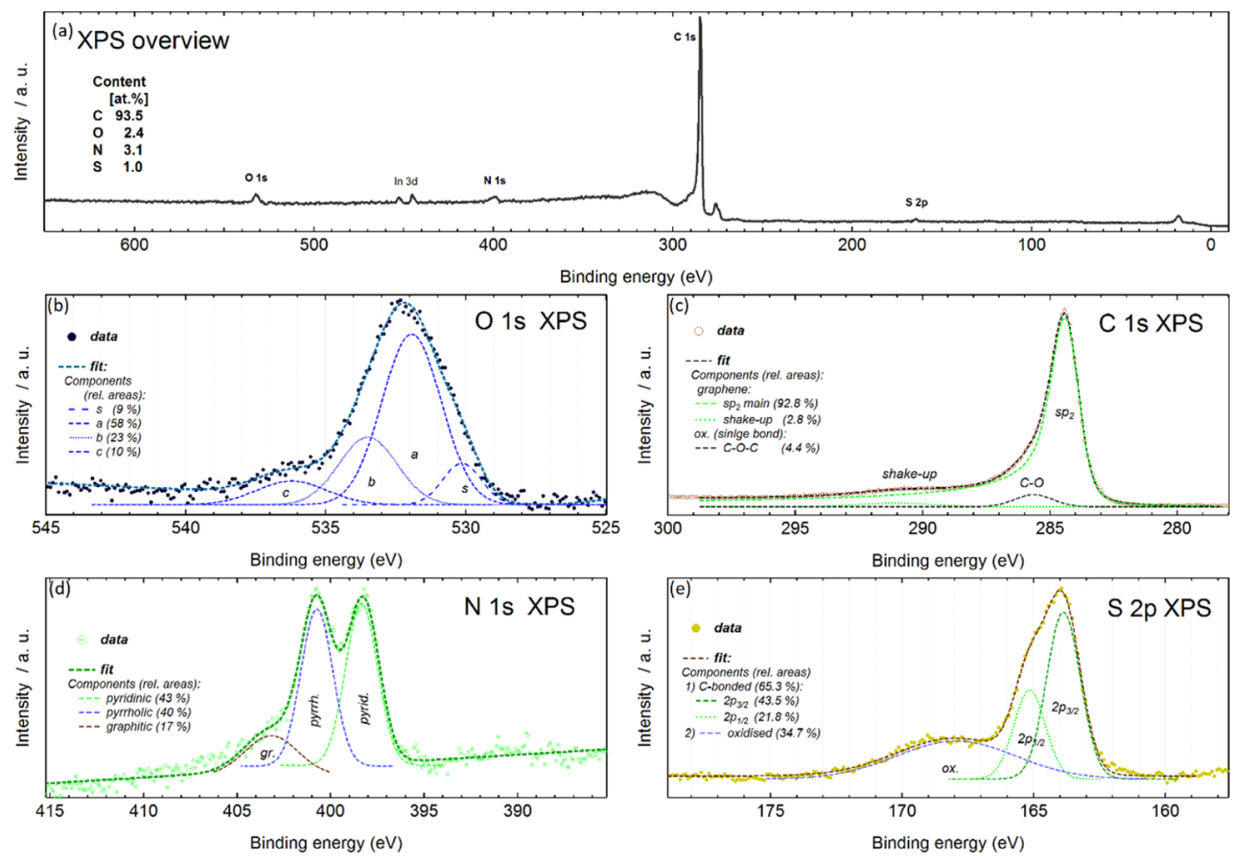

Figure 1. (a) Overview XPS spectrum of 1:5 C/oMUS; high-resolution spectra of (b) O 1s, (c) C 1s, (d) N 1s, and (e) S 2p.

various oxidized forms were computed and the most energetically favorable one (pyridine $\mathrm{N}$-oxide) was used in further calculations. The next step was to calculate the N,S,Odoped graphene with $\mathrm{O}_{2}$ in different positions, and again, the most energetically favorable form was chosen.

To study the stability of the various $\mathrm{O}_{2}$ adsorbates along with $\mathrm{O}_{2}$ protonated species involved in the ORR on the N,Sdoped GO, the adsorption energy $\left(E_{\mathrm{ads}}\right)$ was evaluated as follows

$$
E_{\text {ads }}=E_{\text {adsorbate } / \mathrm{GrO}-\mathrm{NS}}-E_{\text {adsorbate }}-E_{\mathrm{GrO}-\mathrm{NS}}
$$

where $E_{\text {adsorbate/GrO-NS }}, E_{\text {adsorbate, }}$ and $E_{\text {GrO-NS }}$ are gas-phase total energies of the adsorbate together with GrO-NS, the isolated adsorbate, and GrO-NS, respectively. A negative value of $E_{\text {ads }}$ indicates the exothermic adsorption process. The four-electron ORR mechanisms were investigated on the GrO-NS in the present study. In the acidic medium, each ORR step is defined as follows $(*=\mathrm{GrO}-\mathrm{NS})^{38}$

$$
\begin{aligned}
& \mathrm{O}_{2}+{ }^{*}+4\left[\mathrm{H}^{+}+\mathrm{e}^{-}\right] \rightarrow \mathrm{O}_{2}^{*}+4\left[\mathrm{H}^{+}+\mathrm{e}^{-}\right] \\
& \mathrm{O}_{2}^{*}+4\left[\mathrm{H}^{+}+\mathrm{e}^{-}\right] \rightarrow\left[\mathrm{O}^{*}+\mathrm{HO}^{*}\right]+3\left[\mathrm{H}^{+}+\mathrm{e}^{-}\right] \\
& \quad\left[\mathrm{O}^{*}+\mathrm{HO}^{*}\right]+3\left[\mathrm{H}^{+}+\mathrm{e}^{-}\right] \\
& \quad \rightarrow\left[\mathrm{HO}^{*}+\mathrm{HO}^{*}\right]+2\left[\mathrm{H}^{+}+\mathrm{e}^{-}\right] \\
& \quad\left[\mathrm{HO}^{*}+\mathrm{HO}^{*}\right]+2\left[\mathrm{H}^{+}+\mathrm{e}^{-}\right] \\
& \quad \rightarrow \mathrm{HO}^{*}+\mathrm{H}_{2} \mathrm{O}+\left[\mathrm{H}^{+}+\mathrm{e}^{-}\right] \\
& \mathrm{HO}^{*}+\mathrm{H}_{2} \mathrm{O}+\left[\mathrm{H}^{+}+\mathrm{e}^{-}\right] \rightarrow{ }^{*}+2 \mathrm{H}_{2} \mathrm{O} \\
& \text { Overall: } \mathrm{O}_{2}+4\left[\mathrm{H}^{+}+\mathrm{e}^{-}\right] \rightarrow 2 \mathrm{H}_{2} \mathrm{O}
\end{aligned}
$$

In the alkaline medium, each ORR step is defined as follows

$$
\mathrm{O}_{2}+*+2 \mathrm{H}_{2} \mathrm{O}+4 \mathrm{e}^{-} \rightarrow \mathrm{O}_{2}^{*}+2 \mathrm{H}_{2} \mathrm{O}+4 \mathrm{e}^{-}
$$

$$
\begin{aligned}
& \mathrm{O}_{2}^{*}+2 \mathrm{H}_{2} \mathrm{O}+4 \mathrm{e}^{-} \\
& \rightarrow\left[\mathrm{O}^{*}+\mathrm{HO}^{*}\right]+\mathrm{H}_{2} \mathrm{O}+\mathrm{HO}^{-}+3 \mathrm{e}^{-} \\
& {\left[\mathrm{O}^{*}+\mathrm{HO}^{*}\right]+\mathrm{H}_{2} \mathrm{O}+\mathrm{HO}^{-}+3 \mathrm{e}^{-}} \\
& \quad \rightarrow\left[\mathrm{HO}^{*}+\mathrm{HO}^{*}\right]+2 \mathrm{HO}^{-}+2 \mathrm{e}^{-} \\
& {\left[\mathrm{HO}^{*}+\mathrm{HO}^{*}\right]+2 \mathrm{HO}^{-}+2 \mathrm{e}^{-} \rightarrow \mathrm{HO}^{*}+3 \mathrm{HO}^{-}+\mathrm{e}^{-}} \\
& \mathrm{HO}^{*}+3 \mathrm{HO}^{-}+\mathrm{e}^{-} \rightarrow *+4 \mathrm{HO}^{-} \\
& \text {Overall: } \mathrm{O}_{2}+2 \mathrm{H}_{2} \mathrm{O}+4 \mathrm{e}^{-} \rightarrow 4 \mathrm{HO}^{-}
\end{aligned}
$$

Finally, the energy diagrams of ORR were estimated in accordance with the method proposed by Nørskov et al. ${ }^{39}$ using eq 14

$$
\Delta G=\Delta E+\Delta \mathrm{ZPE}-T \Delta S+\Delta G_{\mathrm{U}}+\Delta G_{\mathrm{pH}}
$$

where $\Delta E$ is the energy difference between the products and the reactants (eqs 2-13), $\Delta \mathrm{ZPE}$ and $\Delta S$ are the zero-point correction to the total energy and correction to the entropy, respectively, $T$ is the temperature $(298.15 \mathrm{~K}) ; \Delta G_{U}=-n e U$, where $n, e$, and $U$ denote the number of electrons in the reaction, the electron charge, and electrode overpotential with respect to the standard hydrogen electrode, respectively; and $\Delta G_{\mathrm{pH}}=k_{\mathrm{B}} T \ln 10 \times \mathrm{pH}$, where $k_{\mathrm{B}}$ is the Boltzmann constant. In the present study, $\mathrm{pH}=0\left(\Delta G_{\mathrm{pH}}=0\right)$ and $\mathrm{pH}=13\left(\Delta G_{\mathrm{pH}}\right.$ $=0.77 \mathrm{eV})$ were assumed for acidic medium and alkaline medium, respectively. The free energy of $\mathrm{H}_{2} \mathrm{O}$ in bulk water was calculated in the gas phase under a pressure of 0.035 bar (the equilibrium vapor pressure of $\mathrm{H}_{2} \mathrm{O}$ at $298.15 \mathrm{~K}$ ). The total and free energy of $\left[\mathrm{H}^{+}+\mathrm{e}^{-}\right]$in the solution, according to a computational hydrogen electrode model, was estimated as the energy of $1 / 2 \mathrm{H}_{2}$ under standard conditions. The free energy of $\mathrm{HO}^{-}$was obtained from the reaction in equilibrium in the water solution, $\mathrm{H}^{+}+\mathrm{HO}^{-}=\mathrm{H}_{2} \mathrm{O}$. The entropies of the molecules in the gas phase were taken from the NIST 
database. ${ }^{40}$ The ZPE corrections of all species excluding GrONS were obtained from vibrational frequencies.

Note that we omit here the consideration of graphene Soxidized forms in view of a rather low oxygen content (2.4 at. $\%$, see Section 3.1) because this issue deserves special analysis and will be the subject of a separate study.

\section{RESULTS AND DISCUSSION}

3.1. Physical Characterization of the $\mathrm{N}$ - and $\mathrm{S}$ Codoped MWCNT/rGO Composite. The surface chemical composition was studied using XPS. Fitting was performed using the SPANCF curve-fitting macropackage as presented in previous studies. ${ }^{41,42}$ Figure 1a displays an overview spectrum; close-up views of the $\mathrm{O} 1 \mathrm{~s}, \mathrm{~N} 1 \mathrm{~s}, \mathrm{C} 1 \mathrm{~s}$, and $\mathrm{S} 2 \mathrm{p}$ regions are shown in Figure $1 \mathrm{~b}-\mathrm{e}$. The overview spectrum (Figure 1a) shows a dominating carbon content (93.5 at. \%), as well as small quantities of oxygen (2.4 at. \%), nitrogen (3.1 at. \%), and sulfur (1.0 at. \%), also a trace signal from the indium metal substrate. This confirms that $\mathrm{N}$ and $\mathrm{S}$ have been successfully incorporated into the carbon framework and oMUS can be used as a precursor for $\mathrm{N}$ and $\mathrm{S}$ codoping. The $\mathrm{O} 1 \mathrm{~s}$ spectra (Figure 1b) have a broad [full width at half-maximum (fwhm) $\sim 3.5 \mathrm{eV}]$ peak with a maximum at $531.9 \mathrm{eV}$, which suggests dominant $\mathrm{C}-\mathrm{O}$ single bonds. The asymmetry of the high binding energy flank decreasing more slowly might accommodate a minor contribution of doubly bound carbon, although the asymmetry in the $\mathrm{O} 1 \mathrm{~s}$ XPS might have several origins (proximity to a carboxyl radical, as an example). ${ }^{43}$ The C 1s spectra (Figure 1c) have a dominant peak with the maximum at $284.3 \mathrm{eV}$ (fwhm approximately $1.4 \mathrm{eV}$ ) and an asymmetric shape, characteristic of $\mathrm{sp}^{2}$-bonded carbon, viz., in (nonoxidized) graphene. Therefore, to avoid overestimating contributions from any oxidized components, the $\mathrm{C} 1 \mathrm{~s}$ spectrum was primarily fitted with an asymmetric DoniachSunjic line profile suitable for core XPS peaks of samples of metallic character. Second, two minor contributions were introduced, which relate to the shake-up (i.e., kinetic energy loss) feature related to the graphene itself and is a broad feature centered approximately $6 \mathrm{eV}$ above the main graphene $\mathrm{C}$ 1s peak on the binding energy scale and, more significantly, a minor contribution (at the level of $4-5 \%$ of the total $\mathrm{C} 1 \mathrm{~s}$ intensity), which can relate to carbon single bonded to oxygen. The N 1s spectra (Figure 1d) show two well-separated peaks at $398.3 \mathrm{eV}$ and at $400.7 \mathrm{eV}$, which correspond to pyridinic $\mathrm{N}$ and pyrrolic $\mathrm{N}$, respectively, and have very similar spectral weight (of the $\mathrm{N}$ 1s spectral area, the peak areas indicate $43 \%$ pyridinic and $40 \%$ pyrrolic nitrogen positions). The remaining broader spectral feature with its maximum toward higher binding energy with a maximum at approximately $403.2 \mathrm{eV}$ indicates $17 \%$ graphitic nitrogen content. All three configurations of nitrogen (pyridinic N, pyrrolic $\mathrm{N}$, and graphitic N) are recognized as active species for the ORR. ${ }^{44}$ The $S 2 p$ spectra (Figure 1e) with the leading $2 \mathrm{p}_{3 / 2}$ peak at $163.9 \mathrm{eV}$ correspond to $\mathrm{C}-\mathrm{S}-\mathrm{C}$ bonds, and a more diffuse broader feature at higher binding energies centered just below $168 \mathrm{eV}$ binding energy, which corresponds to sulfur oxides, which occur at the edges of the carbon network. ${ }^{45}$

TEM images show that the samples consist of typical multiwall CNTs and graphene/GO layers (Figure 2a). Highresolution TEM images from areas in Figure $2 \mathrm{a}$ and typical hexagonal FFT images originating from two-layer GO are shown in Figure 2b. All over the sample, one layer or

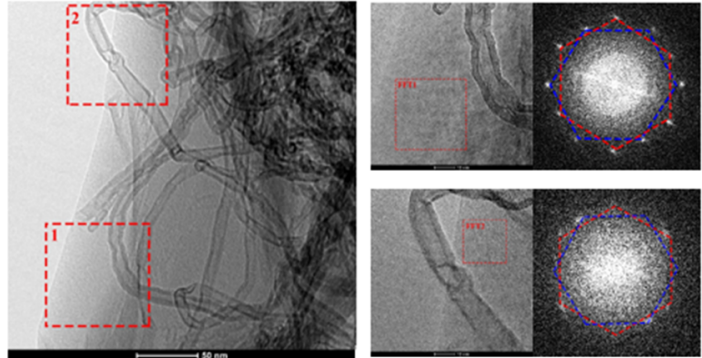

Figure 2. TEM image of the 1:5 C/oMUS catalyst material.

multilayer GO agglomerations together with CNT were observed.

Figure 3 shows the elemental mapping in the 1:5 C/oMUS observed by STEM-EDS. Nitrogen can be clearly found with
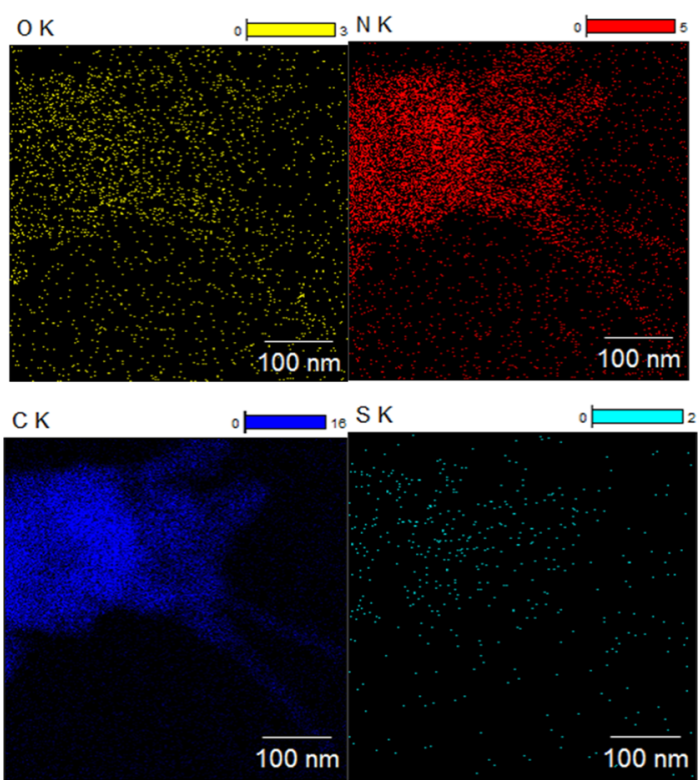

Figure 3. Elemental mapping images of oxygen, nitrogen, carbon, and sulfur in the 1:5 C/oMUS catalyst material.

the same distribution as the carbon, which means the nitrogen was successfully doped into the carbon. The existence of sulfur was also confirmed, but the distribution of which was not such clear because of its content was lower than that of the nitrogen. The high-resolution elemental mapping results are consistent with the XPS, and it can provide the microdistribution of the doping elements, which is helpful to understand the mechanism of the high catalyst efficiency.

3.2. ORR Studies in $0.1 \mathrm{M} \mathrm{KOH}$. The ORR was studied on C/oMUS-modified GC electrodes in $0.1 \mathrm{M} \mathrm{KOH}$ solution at room temperature using the $\mathrm{RDE}$ setup. At first, the ratio of $\mathrm{C}$ and oMUS was varied. The results in $0.1 \mathrm{M} \mathrm{KOH}$ at a rotating speed of $1900 \mathrm{rpm}$ are shown in Figure 4. The best ratio was $1: 5$. The differences between ratios of $1: 5$ and $1: 2.5$ are not significant but increasing the precursor dose has an influence on ORR onset and half-wave potential. However, one can also see from Figure 4 that the overdosing of the doping precursor has a strong effect on the electrocatalytic activity. Both the onset and half-wave potential of the 1:7.5 C/oMUS are shifted to much more negative potentials, and the performance of the electrocatalyst drops drastically. This phenomenon could be caused by the minor and hardly 


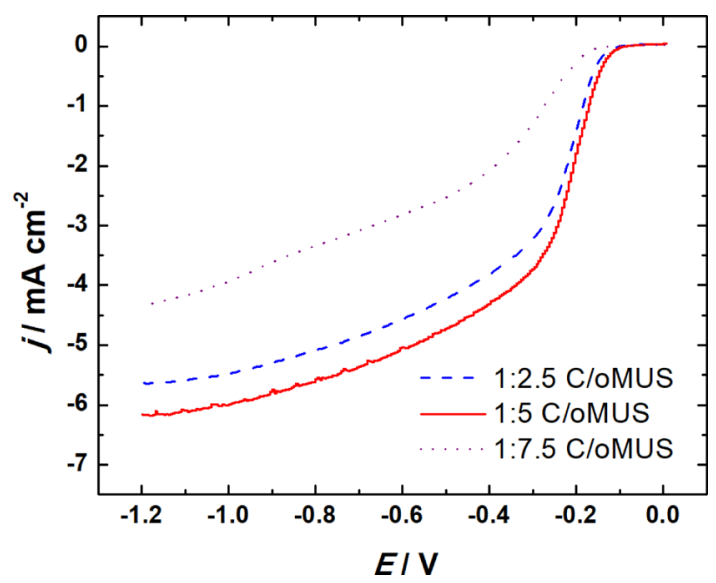

Figure 4. RDE voltammetry curves for ORR on modified GC electrodes in $\mathrm{O}_{2}$-saturated 0.1 M KOH. $\nu=10 \mathrm{mV} \mathrm{s}^{-1}, \omega=1900 \mathrm{rpm}$.

recognizable change in the catalyst structure and porosity which is reportedly related to the change of the doping agent concentration. ${ }^{46}$ Apparently, the change in the doping agent to carbon ratio can also hamper the electrocatalytic activity of graphene type materials by unwanted change in the graphene lattice structure which in turn will result in reduced number of edge defects and active sites. ${ }^{47} \mathrm{~A}$ higher doping agent to carbon ratio creates more defects to the $\mathrm{sp}^{2}$-carbon network and thereby reduces electrical conductivity of the carbon network. $^{48}$

To evaluate the effect of pyrolysis temperature, the 1:5 C/ oMUS was also pyrolyzed at different temperatures, as it can be seen from Figure 5. The best electrochemical activity was

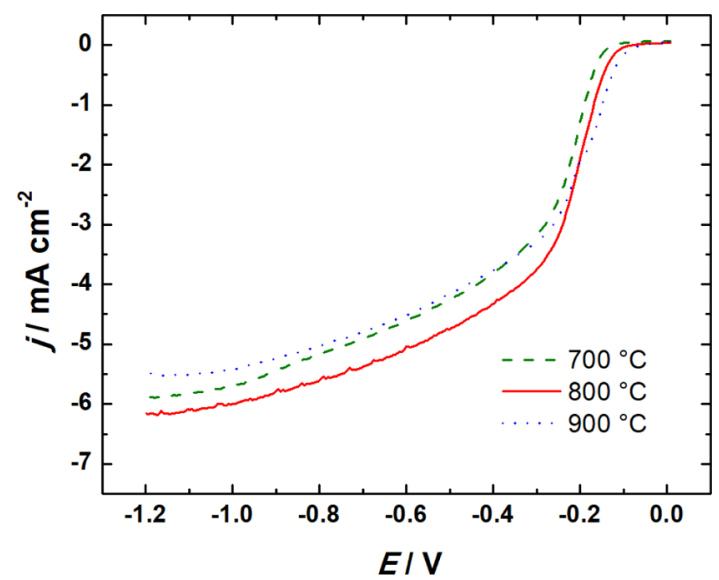

Figure 5. RDE voltammetry curves for ORR on modified GC electrodes pyrolyzed at different temperatures in $\mathrm{O}_{2}$-saturated $0.1 \mathrm{M}$ KOH. $\nu=10 \mathrm{mV} \mathrm{s}^{-1}, \omega=1900 \mathrm{rpm}$.

achieved when the pyrolysis was carried out at $800{ }^{\circ} \mathrm{C}$. For the catalyst heat treated at $900{ }^{\circ} \mathrm{C}$, the onset and half-wave potentials are even a bit better, but the limiting current values decrease notably at more negative potentials. This could be attributed to carbon reconstruction to heal the defects and damaging of topological defect active sites which can occur at $900{ }^{\circ} \mathrm{C}$ and above. ${ }^{49}$ Previous studies have shown that the low pyrolysis temperature can result in lower limiting current densities as well poor conductivity of the material, whereas if the heating temperature is too high, then the amount of structural defects can be few and limiting current densities of the catalyst can again be suppressed. ${ }^{50,51}$ Therefore, we can assume that the pyrolysis of carbon in the presence of oMUS at $800{ }^{\circ} \mathrm{C}$ can provide right amount of defects and exposed edges for the ORR, which however is rather speculative as an exact reason for the catalytic change and the chemical nature and the amount of active sites for the ORR on this type of catalysts are still under debate. It is also proposed that heteroatom doping of carbon materials below $800{ }^{\circ} \mathrm{C}$ can result from the lower carbonization degree of the catalyst, whereas higher temperatures may result from the higher decomposition degree of the heteroatom species leading to lower electrocatalytic activity. ${ }^{52,53}$ It is worth noting that pyrolysis at different temperatures can also tailor the contents of the different $\mathrm{N}$ configurations (graphitic $\mathrm{N}$, pyridinic $\mathrm{N}$, and pyrrolic $\mathrm{N}$ ) in $\mathrm{C} /$ oMUS catalysts. Specially, the pyridinic $\mathrm{N}$ content, which is confirmed to be one of the key factors, to be related to the activity of the ORR. ${ }^{54}$

The ORR results for the 1:5 C/oMUS catalyst material are shown in Figure 6a. The onset potential for this material is $-0.08 \mathrm{~V}$, and the catalytic current is increasing with increasing rotation speed, indicating that the process is under diffusion control. The Koutecky-Levich $(\mathrm{K}-\mathrm{L})$ plots were also constructed (Figure $6 \mathrm{~b}$ ) using the $\mathrm{O}_{2}$ reduction reaction polarization data shown in Figure 6a. This was done using the $\mathrm{K}-\mathrm{L}$ equation ${ }^{55}$

$$
\frac{1}{j}=\frac{1}{j_{\mathrm{k}}}+\frac{1}{j_{\mathrm{d}}}=-\frac{1}{n F k c_{\mathrm{O}_{2}}^{\mathrm{b}}}-\frac{1}{0.62 n F D_{\mathrm{O}_{2}}^{2 / 3} \nu^{-1 / 6} c_{\mathrm{O}_{2}}^{\mathrm{b}} \omega^{1 / 2}}
$$

where $j$ is the current density measured experimentally, $j_{\mathrm{k}}$ and $j_{\mathrm{d}}$ are the kinetic and diffusion limited current densities, respectively, $k$ is the electrochemical rate constant for $\mathrm{O}_{2}$ reduction, $c_{\mathrm{O}_{2}}^{\mathrm{b}}$ is the concentration of oxygen in the bulk $(1.2 \times$ $\left.10^{-6} \mathrm{~mol} \mathrm{~cm}{ }^{-3}\right),{ }^{56} \mathrm{~F}$ is the Faraday constant $\left(96485 \mathrm{C} \mathrm{mol}^{-1}\right)$, $\mathrm{D}_{\mathrm{O}_{2}}$ is the diffusion coefficient of $\mathrm{O}_{2}$ in $0.1 \mathrm{M} \mathrm{KOH}(1.9 \times$ $\left.10^{-5} \mathrm{~cm}^{2} \mathrm{~s}^{-1}\right),{ }^{56} \nu$ is the kinematic viscosity of the solution $\left(0.01 \mathrm{~cm}^{2} \mathrm{~s}^{-1}\right)$, and $\omega$ is the rotation rate of the electrode ( $\mathrm{rad}$ $\left.\mathrm{s}^{-1}\right) .{ }^{57}$ The $\mathrm{K}-\mathrm{L}$ plots are linear, and extrapolating them to $y$ axis, the intercept is near zero, indicating that in the studied potential range, the reduction process is diffusion limited. The number of electrons transferred per $\mathrm{O}_{2}$ molecules $(n)$ was also calculated. At higher negative potentials, the number of electrons transferred per $\mathrm{O}_{2}$ molecule is 4 ; at more positive potential, it drops a bit. The limiting current density for 1900 $\mathrm{rpm}$ was $-6.16 \mathrm{~mA} \mathrm{~cm}^{-2}$ (Figure $6 \mathrm{a}$ ). This is very similar to the expected value obtained from the $\mathrm{K}-\mathrm{L}$ eq 15 which was $-6.21 \mathrm{~mA} \mathrm{~cm}^{-2}$.

The enhanced ORR performance was achieved because of $\mathrm{N}$ - and S-codoping. As the difference of electronegativity between carbon (2.55) and nitrogen (3.04) is quite large, this created favorable sites for $\mathrm{O}_{2}$ surface adsorption. ${ }^{20}$ The bonding of oxygen is weakened, and a four-electron reduction process is happening at the electrode. As the electronegativity between carbon (2.55) and sulfur (2.58) is quite similar, it could mean that doping with $S$ has no effect on the ORR. However, two lone pairs of electrons on sulfur can have effect on the interaction with $\mathrm{O}_{2}$, it can easily donate electron, and as a result, four-electron reduction may happen. Sulfur due to its large atomic radius $(110 \mathrm{ppm})$ can also cause defects in the carbon structure, which creates a charge difference what facilitates the $\mathrm{O}_{2}$ chemisorption. ${ }^{58,59}$ 

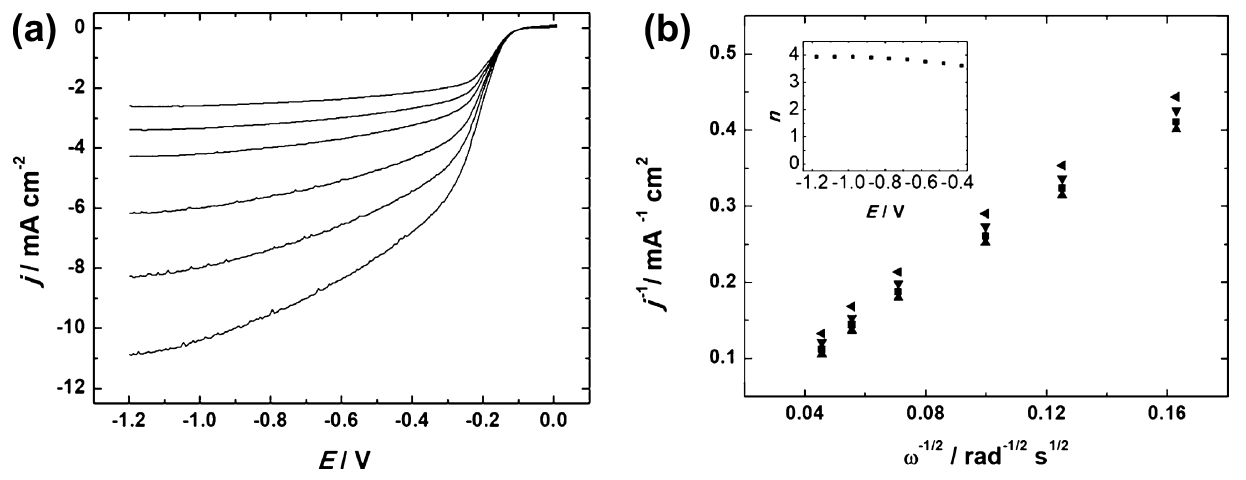

Figure 6. (a) RDE polarization curves for oxygen reduction on GC electrodes modified with 1:5 C/oMUS in $\mathrm{O}_{2}$ saturated $0.1 \mathrm{M} \mathrm{KOH}$. $\nu=10 \mathrm{mV}$ $\mathrm{s}^{-1}, \omega=(1) 360$, (2) 610, (3) 960, (4) 1900, (5) 3100, and (6) $4600 \mathrm{rpm}$; (b) K-L plots for oxygen reduction on the 1:5 C/oMUS electrode in $0.1 \mathrm{M} \mathrm{KOH}$ at various potentials. The inset figure shows the changes of $n$ values in studied potential range.

Although there are reports that the introduction of $\mathrm{N}$ doping can effectively improve the ORR catalytic activity of carbon, the identity and role of the electrocatalytically active center are still controversial as its contribution to catalytic activity is not well defined. Pyridinic $\mathrm{N}$ modifies the band structure of carbon, raising the density of $\mathrm{p}$ states near the Fermi level and lowering the work function. However, pyridinic $\mathrm{N}$ alone is not an effective promoter for ORR activity of carbon, as evidenced by the sluggish ORR activity beforehand. At the same time, the relative electronegativity of graphitic $\mathrm{N}$ reduces the electron density on the adjacent $\mathrm{C}$ nuclei, which helps electron transfer from the adjacent $\mathrm{C}$ to $\mathrm{N}$ atoms, and $\mathrm{N}$ back donates electrons to adjacent $\mathrm{C} p$ orbitals. $^{60,61}$ Figure 7 compares the $\mathrm{RDE}$

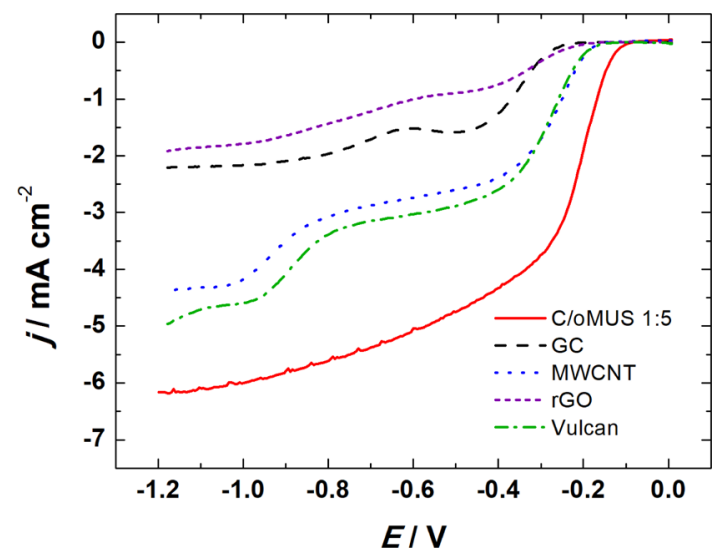

Figure 7. RDE voltammetry curves for ORR on unmodified GC, MWCNTs, rGO, Vulcan carbon, and C/oMUS 1:5 modified GC electrodes in $\mathrm{O}_{2}$-saturated $0.1 \mathrm{M} \mathrm{KOH} . \nu=10 \mathrm{mV} \mathrm{s}^{-1}, \omega=1900 \mathrm{rpm}$.

results for the NS-doped nanocarbon material along with GC, undoped MWCNTs, rGO, and Vulcan carbon to better express the activity trends of the NS-doping. The ORR onset potential for C/oMUS is about $80 \mathrm{mV}$ higher than that of the MWCNTs and close to $150 \mathrm{mV}$ higher than that for the GC. Rather low limiting current densities of the rGO are most probably caused by the restacking and ionomer related effects. One can also see that C/oMUS has lost the two-wave polarization curve structure typical to the carbon catalysts in alkaline media. Thereby, it is evident that the ORR reaction pathway and mechanism have changed because of NS-doping of the carbon.

For the easy comparison of C/oMUS 1:5 with other similar heteroatom-doped catalysts, the mass activity was also calculated. The most often used potential for determining the mass activity of a catalyst is $-0.2 \mathrm{~V}$. The mass activity of $1: 5 \mathrm{C} / \mathrm{oMUS}$ at $-0.2 \mathrm{~V}$ is $4.89 \mathrm{~A} \mathrm{~g}^{-1}$. This is noticeably better than other doped carbon materials, for example, the ones investigated by Pašti et al. which had mass activities from 0.5 to $3.5 \mathrm{~A} \mathrm{~g}^{-1} .62$

As the durability and methanol tolerance of the catalyst material are some of the key parameters of an electrocatalyst, chronoamperometry was conducted with the most active electrocatalyst. The measurement was carried out for $20 \mathrm{~h}$ in $\mathrm{O}_{2}$-saturated $0.1 \mathrm{M} \mathrm{KOH}$. The constant voltage was set at 0.45 $\mathrm{V}$ versus SCE by using the stationary electrode. At first, the current density drops, but then it stabilizes. The catalyst material is relatively stable during the whole experiment. To verify the methanol tolerance of the catalyst material, the $3 \mathrm{M}$ $\mathrm{MeOH}$ was also added to the solution while carrying out the chronoamperometry measurements. The $3 \mathrm{M} \mathrm{MeOH}$ was added at exactly $10 \mathrm{~h}$ and as it can be seen from Figure 8, there

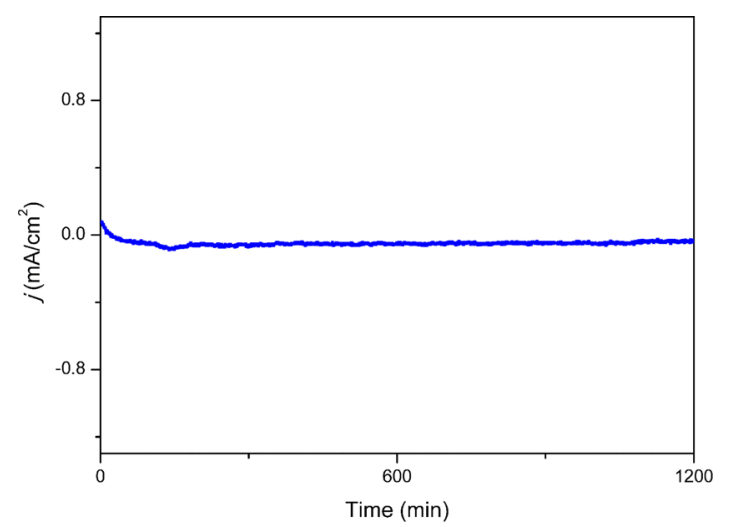

Figure 8. Chronoamperometric response of 1:5 C/oMUS at $-0.45 \mathrm{~V}$ (vs SCE) in $\mathrm{O}_{2}$-saturated $0.1 \mathrm{M} \mathrm{KOH}$.

is no noticeable drop of the current density. Zhang et al. have also conducted chronoamperometry measurements on nitrogen-doped $\mathrm{rGO}$, where $\mathrm{Co}_{3} \mathrm{O}_{4}$ nanoparticles were also anchored on the heteroatom-doped carbon material. ${ }^{63}$ However, their results showed that the addition of $3 \mathrm{M}$ methanol had clear effect to the ORR activity as the current density dropped and did not reach the initial state till the end of the experiment.

3.3. DFT Calculations. For DFT calculations, a graphene sheet of $\mathrm{C}_{54} \mathrm{H}_{18}$ la was chosen and doped with nitrogen and 
sulfur atoms to give structure $\mathbf{1 b}$ which correlates in composition with the XPS data (Figure 9). Because the

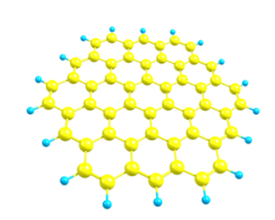

1a

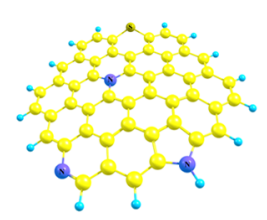

$1 \mathrm{~b}$

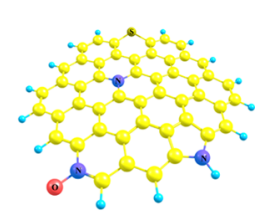

Figure 9. Nondoped $\mathrm{C}_{54} \mathrm{H}_{18}$ (1a), N,S-doped $\mathrm{C}_{49} \mathrm{H}_{15} \mathrm{~N}_{3} \mathrm{~S}$ (1) ), and oxidized N,S-doped $\mathrm{C}_{49} \mathrm{H}_{15} \mathrm{~N}_{3} \mathrm{SO}$ (1c) graphene sheets.

catalyst used in the experiment was partially oxidized (rGO), we have tested various $\mathrm{C}$-oxidized isomers of the epoxide and pyridine $\mathrm{N}$-oxide structures. The pyridine $\mathrm{N}$-oxide form of the rGO-N,S 1c corresponds to the global minimum, with the energy of formation of $\sim 0.87 \mathrm{eV}$. Therefore, structure 1c was chosen for ORR simulation.

On the next step, we tested structure $1 \mathrm{c}$ to find the most favorable active site for adsorption of oxygen using as a criterion the Mulliken positive charges on the carbon atoms. Structure $\mathbf{2 a}$ in Figure 10, in which the $\mathrm{O}_{2}$ molecule is adsorbed over the $\mathrm{C}_{\alpha}-\mathrm{C}_{\beta}$ bond at the graphitic nitrogen atom, is most energetically favorable $\left(E_{\mathrm{ads}}=-1.14 \mathrm{eV}\right)$ and corresponds to the global minimum among other local minima. The $\mathrm{O}-\mathrm{O}$ distance in structure $2 \mathrm{a}$ increases by $0.263 \AA$ with respect to that in free $\mathrm{O}_{2}$ molecule and equals to $1.478 \AA$ A.

Protonation of the $\mathrm{O}-\mathrm{O}$ moiety in $\mathrm{O}_{2} * 2 \mathrm{a}$ by $\left[\mathrm{H}^{+}+\mathrm{e}^{-}\right]$ occurs with rupture of the $\mathrm{O}-\mathrm{O}$ bond with the formation of the adduct [ $\left.\mathrm{O}^{*} \mathrm{HO}^{*}\right](3)$, thus excluding the two-electron ORR pathway. The $\mathrm{O}-\mathrm{O}$ bond breaking was also found to occur when the cationic or anionic form of 3 was protonated. Adduct 3 is characterized by $E_{\mathrm{ads}}=-1.41 \mathrm{eV}$, which is $0.27 \mathrm{eV}$ lower than that of $\mathrm{O}_{2} *(2 \mathrm{a})$. Further protonation of 3 with $\left[\mathrm{H}^{+}\right.$ $\left.+\mathrm{e}^{-}\right]$in direction to $\mathrm{O}^{*}$ or $\mathrm{HO}^{*}$ results in the formation of diol $\left[\mathrm{HO}^{*} \mathrm{HO}^{*}\right] 4$ with a small exothermic effect, $E_{\mathrm{ads}}=$ $-0.01 \mathrm{eV}$ with respect to 3 . Third, the $\left[\mathrm{H}^{+}+\mathrm{e}^{-}\right]$transfer to 4 produces the molecule of water and adduct $\mathrm{HO}^{*}, \mathbf{5}$, which is the most stable species in the series $2-5\left(E_{\mathrm{ads}}=-1.51 \mathrm{eV}\right)$.

According to eqs 2-14, the free-energy diagrams were drawn for reduction of $\mathrm{O}_{2}$ on rGO-N,S 1c at different electrode overpotentials $U$ in acidic and alkaline media (Figure 11). As follows from the diagram, in both media, the adsorption of oxygen on the surface of the catalyst expectedly gives rise to the increase of the free energy by $0.81 \mathrm{eV}$ because of the entropy losses upon adsorption. The development of the ORR in the acidic medium gradually decreases the free energy down to $U=0.85 \mathrm{~V}$, when the free energies of the intermediates $3\left[\mathrm{H}^{+}+\mathrm{e}^{-}\right]+\mathrm{O}^{*}+\mathrm{HO}^{*}$ and $2\left[\mathrm{H}^{+}+\mathrm{e}^{-}\right]+$ $2 \mathrm{HO}^{*}$ become equal. Further increase of overpotential to $U=$ $1.23 \mathrm{~V}$ (corresponding to the equilibrium in the system $2 \mathrm{H}_{2}+$ $\mathrm{O}_{2} \leftrightarrows 2 \mathrm{H}_{2} \mathrm{O}$ ) results in that all intermediates lie in the diagram above the initial or final level of the system, so that all oxygen species are ablated from the surface of the catalyst. If to exclude from consideration the step of molecular oxygen adsorption on the active site of the catalyst, the ratedetermining step in the acidic medium for overpotentials $U$ $>0.85 \mathrm{~V}$ is the second protonation step leading to the formation of diol $2 \mathrm{HO}^{*}$.

In the alkaline medium, at small negative overpotentials, the reduction of $\mathrm{O}_{2} *$ ORR proceeds in a barrierless fashion with monotonous free-energy decrease. At overpotential $U=0.0 \mathrm{~V}$, the free energy of intermediate $\mathrm{HO}^{*}$ is lower than that of the product of the reaction $(-0.04 \mathrm{eV})$ and, hence, the final step of ORR will be rate-determining. This trend is retained for positive overpotentials in alkaline media, up to the equilibrium overpotential $(0 \mathrm{~V}<U<0.46 \mathrm{~V})$. However, when overpotential leading to equilibrium in the system $(U=0.46$
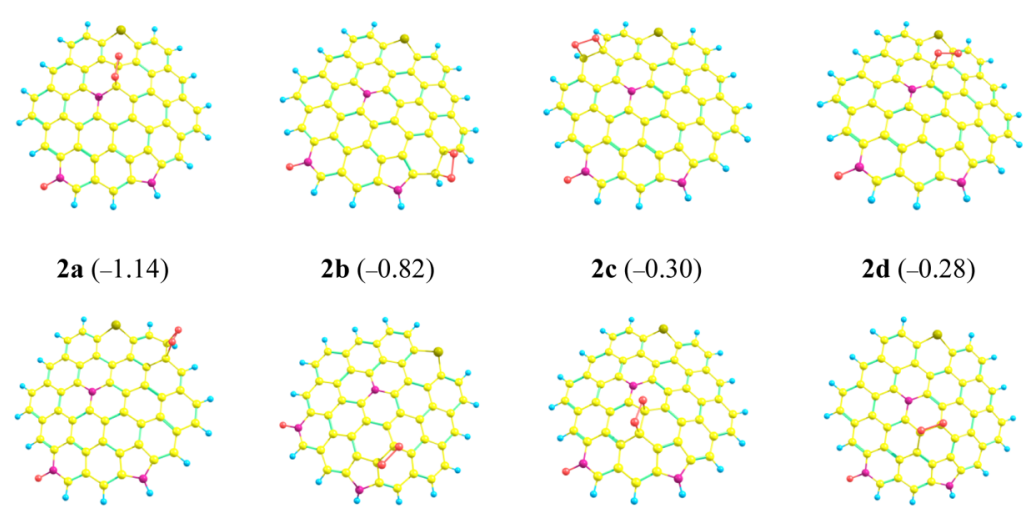

$2 \mathbf{b}(-0.82)$
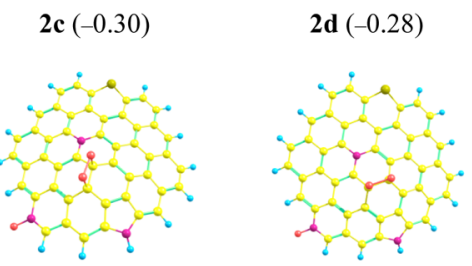

$2 \mathrm{e}(-0.17)$

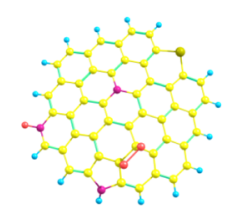

$2 f(0.09)$

$2 \mathrm{~g}(0.19)$

2h (0.26)

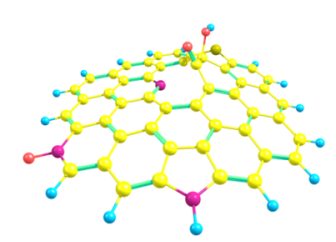

$3(-1.41)$

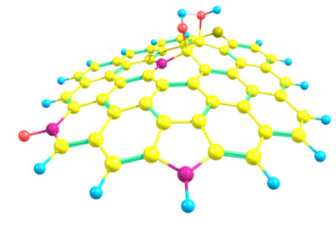

$4(-1.42)$

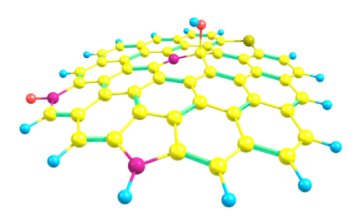

$5(-1.52)$

Figure 10. Structures of $\mathrm{O}_{2} *(\mathbf{2 a}-\mathbf{h})$, reduced forms [O* $\left.\mathrm{HO}^{*}\right]$ (3), [HO* HO*] (4), and $\mathrm{HO} *(\mathbf{5})$ adsorbed on rGO-N,S (1c, Figure 9). In brackets: $E_{\text {ads }}(\mathrm{eV})$ with respect to nonreacting molecules: $\mathrm{O}_{2}, \mathrm{OOH}, \mathrm{H}_{2} \mathrm{O}_{2}$, and $\mathrm{OH}$. Yellow-carbon, blue-hydrogen, red-oxygen, magentanitrogen, and olive-sulfur. 

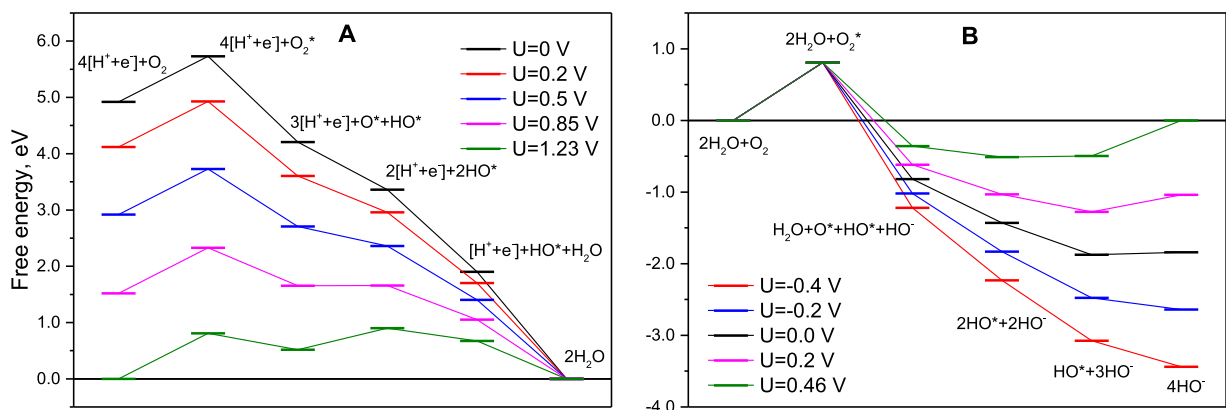

Figure 11. Free-energy diagrams for the reduction of $\mathrm{O}_{2}$ on rGO-N,S $1 \mathrm{c}$ at different electrode overpotentials $U$ in acidic (A) and alkaline (B) media.

$\mathrm{V})$ is applied, the most favorable structure is the one corresponding to intermediate $2 \mathrm{HO}^{*}$, whose free energy is equal to $(-0.51 \mathrm{eV})$.

However, in a real system, the free-energy increase in the step of adsorption must be much smaller, or the free energy may even decrease. The point is that oxygen is supplied to the cathode either in the dissolved form or through porous membranes, in other words, in the form in which it already interacts with other species. This, in turn, means that the entropy losses will be much smaller than those calculated for adsorption of pure gaseous molecular oxygen on the catalyst and may be even outweighed by the energy gain because of adsorption.

\section{CONCLUSIONS}

A novel and effective approach has been used to prepare the nitrogen- and sulfur-codoped carbon catalyst for the ORR. The NS-doped carbon catalyst was synthesized by using the heat treatment of the mixture of GO and multi-walled CNTs together with oMUS. This NS-codoped catalyst provides a valuable template to explore the heteroatom codoping effects toward ORR. As it is almost impossible to detect the exact catalytic site and the reaction mechanism for the ORR on the NS-codoped carbon catalyst by using only electrochemical and physical characterization methods, then DFT calculations were carried out. DFT simulations on graphene doped with nitrogen and sulfur atoms were chosen according to the XPS data and ORR test results. It was found that the $\mathrm{C}_{\alpha}$ and $\mathrm{C}_{\beta}$ carbon atoms at the graphitic nitrogen located close to the sulfur atom, correspond to the global minimum, and are thereby energetically most favorable $(-1.14 \mathrm{eV})$ for the oxygen electroreduction. It is also clear from the current results that the NScodoped catalysts are interesting candidates for various practical applications such as metal-air batteries and fuel cells and thereby the reaction mechanisms of these catalysts are worth of further study.

\section{AUTHOR INFORMATION}

\section{Corresponding Author}

*E-mail: ivar.kruusenberg@kbfi.ee. Phone: +372-5036963.

\section{ORCID}

Andris Sutka: 0000-0002-5739-0164

Bagrat A. Shainyan: 0000-0002-4296-7899

Ivar Kruusenberg: 0000-0002-8199-9324

\section{Notes}

The authors declare no competing financial interest.

\section{ACKNOWLEDGMENTS}

This research was financially supported by ERA.Net RUS Plus funding mechanism (Project HeDoCat) and by the European Regional Development Fund project TK134.

\section{REFERENCES}

(1) Sealy, C. The Problem with Platinum. Mater. Today 2008, 11, 65-68.

(2) Ferreira, P. J.; la O', G. J.; Shao-Horn, Y.; Morgan, D.; Makharia, R.; Kocha, S.; Gasteiger, H. A. Instability of Pt/C Electrocatalysts in Proton Exchange Membrane Fuel Cells. J. Electrochem. Soc. 2005, 152, A2256.

(3) Ratso, S.; Kruusenberg, I.; Joost, U.; Saar, R.; Tammeveski, K. Enhanced Oxygen Reduction Reaction Activity of Nitrogen-Doped Graphene/Multi-Walled Carbon Nanotube Catalysts in Alkaline Media. Int. J. Hydrogen Energy 2016, 41, 22510-22519.

(4) Ratso, S.; Kruusenberg, I.; Vikkisk, M.; Joost, U.; Shulga, E.; Kink, I.; Kallio, T.; Tammeveski, K. Highly Active Nitrogen-Doped Few-Layer Graphene/Carbon Nanotube Composite Electrocatalyst for Oxygen Reduction Reaction in Alkaline Media. Carbon 2014, 73, 361-370.

(5) Vikkisk, M.; Kruusenberg, I.; Ratso, S.; Joost, U.; Shulga, E.; Kink, I.; Rauwel, P.; Tammeveski, K. Enhanced Electrocatalytic Activity of Nitrogen-Doped Multi-Walled Carbon Nanotubes towards the Oxygen Reduction Reaction in Alkaline Media. RSC Adv. 2015, 5, 59495-59505.

(6) Inamdar, S.; Choi, H.-S.; Wang, P.; Song, M. Y.; Yu, J.-S. SulfurContaining Carbon by Flame Synthesis as Efficient Metal-Free Electrocatalyst for Oxygen Reduction Reaction. Electrochem. Commun. 2013, 30, 9-12.

(7) Klingele, M.; Pham, C.; Vuyyuru, K. R.; Britton, B.; Holdcroft, S.; Fischer, A.; Thiele, S. Sulfur Doped Reduced Graphene Oxide as Metal-Free Catalyst for the Oxygen Reduction Reaction in Anion and Proton Exchange Fuel Cells. Electrochem. Commun. 2017, 77, 71-75.

(8) Choi, C. H.; Chung, M. W.; Park, S. H.; Woo, S. I. Additional Doping of Phosphorus and/or Sulfur into Nitrogen-Doped Carbon for Efficient Oxygen Reduction Reaction in Acidic Media. Phys. Chem. Chem. Phys. 2013, 15, 1802-1805.

(9) Biddinger, E. J.; von Deak, D.; Ozkan, U. S. Nitrogen-Containing Carbon Nanostructures as Oxygen-Reduction Catalysts. Top. Catal. 2009, 52, 1566-1574.

(10) Chen, P.; Wang, L.-K.; Wang, G.; Gao, M.-R.; Ge, J.; Yuan, W.J.; Shen, Y.-H.; Xie, A.-J.; Yu, S.-H. Nitrogen-Doped Nanoporous Carbon Nanosheets Derived from Plant Biomass: An Efficient Catalyst for Oxygen Reduction Reaction. Energy Environ. Sci. 2014, 7, 4095-4103.

(11) Guo, Q.; Zhao, D.; Liu, S.; Chen, S.; Hanif, M.; Hou, H. FreeStanding Nitrogen-Doped Carbon Nanotubes at Electrospun Carbon Nanofibers Composite as an Efficient Electrocatalyst for Oxygen Reduction. Electrochim. Acta 2014, 138, 318-324.

(12) Wong, W. Y.; Daud, W. R. W.; Mohamad, A. B.; Kadhum, A. A. H.; Majlan, E. H.; Loh, K. S. Nitrogen-Containing Carbon Nanotubes 
as Cathodic Catalysts for Proton Exchange Membrane Fuel Cells. Diam. Relat. Mater. 2012, 22, 12-22.

(13) Sheng, Z.-H.; Gao, H.-L.; Bao, W.-J.; Wang, F.-B.; Xia, X.-H. Synthesis of Boron Doped Graphene for Oxygen Reduction Reaction in Fuel Cells. J. Mater. Chem. 2012, 22, 390-395.

(14) Wang, L.; Dong, H.; Guo, Z.; Zhang, L.; Hou, T.; Li, Y. Potential Application of Novel Boron-Doped Graphene Nanoribbon as Oxygen Reduction Reaction Catalyst. J. Phys. Chem. C 2016, 120, 17427-17434.

(15) Yang, L.; Jiang, S.; Zhao, Y.; Zhu, L.; Chen, S.; Wang, X.; Wu, Q.; Ma, J.; Ma, Y.; Hu, Z. Boron-Doped Carbon Nanotubes as MetalFree Electrocatalysts for the Oxygen Reduction Reaction. Angew. Chem. Int. Ed. 2011, 50, 7132-7135.

(16) Han, C.; Bo, X.; Zhang, Y.; Li, M.; Guo, L. One-Pot Synthesis of Nitrogen and Sulfur Co-Doped Onion-like Mesoporous Carbon Vesicle as an Efficient Metal-Free Catalyst for Oxygen Reduction Reaction in Alkaline Solution. J. Power Sources 2014, 272, 267-276.

(17) Higgins, D. C.; Hoque, M. A.; Hassan, F.; Choi, J.-Y.; Kim, B.; Chen, Z. Oxygen Reduction on Graphene-Carbon Nanotube Composites Doped Sequentially with Nitrogen and Sulfur. ACS Catal. 2014, 4, 2734-2740.

(18) Zhang, H.; Liu, X.; He, G.; Zhang, X.; Bao, S.; Hu, W. Bioinspired Synthesis of Nitrogen/Sulfur Co-Doped Graphene as an Efficient Electrocatalyst for Oxygen Reduction Reaction. J. Power Sources 2015, 279, 252-258.

(19) Qiu, Y.; Huo, J.; Jia, F.; Shanks, B. H.; Li, W. N- and S-Doped Mesoporous Carbon as Metal-Free Cathode Catalysts for Direct Biorenewable Alcohol Fuel Cells. J. Mater. Chem. A 2016, 4, 83-95. (20) Zhang, J.; Dai, L. Heteroatom-Doped Graphitic Carbon Catalysts for Efficient Electrocatalysis of Oxygen Reduction Reaction. ACS Catal. 2015, 5, 7244-7253.

(21) Hua, Y.; Jiang, T.; Wang, K.; Wu, M.; Song, S.; Wang, Y.; Tsiakaras, P. Efficient Pt-Free Electrocatalyst for Oxygen Reduction Reaction: Highly Ordered Mesoporous N and S Co-Doped Carbon with Saccharin as Single-Source Molecular Precursor. Appl. Catal., B 2016, 194, 202-208.

(22) Li, L.; Yu, B.; You, T. Nitrogen and Sulfur Co-Doped Carbon Dots for Highly Selective and Sensitive Detection of $\mathrm{Hg}$ (II) Ions. Biosens. Bioelectron. 2015, 74, 263-269.

(23) Liu, T.; Guo, Y.-F.; Yan, Y.-M.; Wang, F.; Deng, C.; Rooney, D.; Sun, K.-N. CoO Nanoparticles Embedded in Three-Dimensional Nitrogen/Sulfur Co-Doped Carbon Nanofiber Networks as a Bifunctional Catalyst for Oxygen Reduction/Evolution Reactions. Carbon 2016, 106, 84-92.

(24) Wu, M.; Wang, J.; Wu, Z.; Xin, H. L.; Wang, D. Synergistic Enhancement of Nitrogen and Sulfur Co-Doped Graphene with Carbon Nanosphere Insertion for the Electrocatalytic Oxygen Reduction Reaction. J. Mater. Chem. A 2015, 3, 7727-7731.

(25) Liang, J.; Jiao, Y.; Jaroniec, M.; Qiao, S. Z. Sulfur and Nitrogen Dual-Doped Mesoporous Graphene Electrocatalyst for Oxygen Reduction with Synergistically Enhanced Performance. Angew. Chem. Int. Ed. 2012, 51, 11496-11500.

(26) Wang, Y.; Wu, Y.; Huang, Y.; Zhang, F.; Yang, X.; Ma, Y.; Chen, Y. Preventing Graphene Sheets from Restacking for HighCapacitance Performance. J. Phys. Chem. C 2011, 115, 23192-23197.

(27) Wang, X.; Zhi, L.; Müllen, K. Transparent, Conductive Graphene Electrodes for Dye-Sensitized Solar Cells. Nano Lett. 2008, 8, 323-327.

(28) Yan, J.; Wei, T.; Shao, B.; Ma, F.; Fan, Z.; Zhang, M.; Zheng, C.; Shang, Y.; Qian, W.; Wei, F. Electrochemical Properties of Graphene Nanosheet/Carbon Black Composites as Electrodes for Supercapacitors. Carbon 2010, 48, 1731-1737.

(29) Choi, C. H.; Chung, M. W.; Kwon, H. C.; Chung, J. H.; Woo, S. I. Nitrogen-Doped Graphene/Carbon Nanotube Self-Assembly for Efficient Oxygen Reduction Reaction in Acid Media. Appl. Catal., B 2014, 144, 760-766.

(30) Sun, Y.; Wu, J.; Tian, J.; Jin, C.; Yang, R. Sulfur-Doped Carbon Spheres as Efficient Metal-Free Electrocatalysts for Oxygen Reduction Reaction. Electrochim. Acta 2015, 178, 806-812.
(31) Yang, Z.; Yao, Z.; Li, G.; Fang, G.; Nie, H.; Liu, Z.; Zhou, X.; Chen, X. a.; Huang, S.; Chen, X.; et al. Sulfur-Doped Graphene as an Efficient Metal-Free Cathode Catalyst for Oxygen Reduction. ACS Nano 2012, 6, 205-211.

(32) Yang, S.; Zhi, L.; Tang, K.; Feng, X.; Maier, J.; Müllen, K. Efficient Synthesis of Heteroatom (N or S)-Doped Graphene Based on Ultrathin Graphene Oxide-Porous Silica Sheets for Oxygen Reduction Reactions. Adv. Funct. Mater. 2012, 22, 3634-3640.

(33) Jeon, I.-Y.; Zhang, S.; Zhang, L.; Choi, H.-J.; Seo, J.-M.; Xia, Z.; Dai, L.; Baek, J.-B. Edge-Selectively Sulfurized Graphene Nanoplatelets as Efficient Metal-Free Electrocatalysts for Oxygen Reduction Reaction: The Electron Spin Effect. Adv. Mater. 2013, $25,6138-6145$.

(34) Hummers, W. S.; Offeman, R. E. Preparation of Graphitic Oxide. J. Am. Chem. Soc. 1958, 80, 1339.

(35) Kruusenberg, I.; Marandi, M.; Sammelselg, V.; Tammeveski, K. Hydrodynamic Deposition of Carbon Nanotubes onto HOPG: The Reduction of Oxygen on CNT/HOPG Electrodes in Alkaline Solution. Electrochem. Solid-State Lett. 2009, 12, F31-F34.

(36) Frisch, M. J.; Trucks, W.; Schlegel, H. B.; Scuseria, G. E.; Robb, M. A.; Cheeseman, J. R.; Scalmani, G.; Barone, V.; Mennucci, B.; Petersson, G. A.; et al. Gaussian 09, Revision E. 01; Gaussian, Inc.: Wallingford, CT, 2009.

(37) Zhurko, G. A. ChemCraft.

(38) Wang, Y.; Jiao, M.; Song, W.; Wu, Z. Doped Fullerene as a Metal-Free Electrocatalyst for Oxygen Reduction Reaction: A FirstPrinciples Study. Carbon 2017, 114, 393-401.

(39) Nørskov, J. K.; Rossmeisl, J.; Logadottir, A.; Lindqvist, L.; Kitchin, J. R.; Bligaard, T.; Jónsson, H. Origin of the Overpotential for Oxygen Reduction at a Fuel-Cell Cathode. J. Phys. Chem. B 2004, 108, 17886-17892.

(40) NIST. Chemistry WebBook (Accessed 4 April 2019).

(41) Kukk, E.; Snell, G.; Bozek, J. D.; Cheng, W. T.; Berrah, N. Vibrational Structure and Partial Rates of Resonant Auger Decay of the [Formula Presented] Core Excitations in Nitric Oxide. Phys. Rev. A: At., Mol., Opt. Phys. 2001, 63, 062702.

(42) Kukk, E.; Ueda, K.; Hergenhahn, U.; Liu, X. J.; Prümper, G.; Yoshida, H.; Tamenori, Y.; Makochekanwa, C.; Tanaka, T.; Kitajima, M.; et al. Violation of the Franck-Condon Principle Due to Recoil Effects in High Energy Molecular Core-Level Photoionization. Phys. Rev. Lett. 2005, 95, 133001.

(43) Weiss, T.; Zielasek, V.; Bäumer, M. Influence of Water on Chemical Vapor Deposition of $\mathrm{Ni}$ and Co Thin Films from Ethanol Solutions of Acetylacetonate Precursors. Sci. Rep. 2015, 5, 18194.

(44) Chen, J.; Zhang, H.; Liu, P.; Li, Y.; Li, G.; An, T.; Zhao, H. Thiourea Sole Doping Reagent Approach for Controllable N, S CoDoping of Pre-Synthesized Large-Sized Carbon Nanospheres as Electrocatalyst for Oxygen Reduction Reaction. Carbon 2015, 92, 339-347.

(45) Su, Y.; Zhang, Y.; Zhuang, X.; Li, S.; Wu, D.; Zhang, F.; Feng, $X$. Low-Temperature Synthesis of Nitrogen/Sulfur Co-Doped ThreeDimensional Graphene Frameworks as Efficient Metal-Free Electrocatalyst for Oxygen Reduction Reaction. Carbon 2013, 62, 296-301.

(46) Wiggins-Camacho, J. D.; Stevenson, K. J. Effect of Nitrogen Concentration on Capacitance, Density of States, Electronic Conductivity, and Morphology of N-Doped Carbon Nanotube Electrodes. J. Phys. Chem. C 2009, 113, 19082-19090.

(47) Rahsepar, M.; Nobakht, M. R.; Kim, H.; Pakshir, M. Facile Enhancement of the Active Catalytic Sites of N-Doped Graphene as a High Performance Metal-Free Electrocatalyst for Oxygen Reduction Reaction. Appl. Surf. Sci. 2018, 447, 182-190.

(48) Wu, J.; Yang, Z.; Sun, Q.; Li, X.; Strasser, P.; Yang, R. Synthesis and Electrocatalytic Activity of Phosphorus-Doped Carbon Xerogel for Oxygen Reduction. Electrochim. Acta 2014, 127, 53-60.

(49) Chen, T.; Chen, J.; Waki, K. An Activity Recoverable Carbon Nanotube Based Electrocatalysts: Rapid Annealing Effects and Importance of Defects. Carbon 2018, 129, 119-127.

(50) Lu, X.; Li, Z.; Yin, X.; Wang, S.; Liu, Y.; Wang, Y. Controllable Synthesis of Three-Dimensional Nitrogen-Doped Graphene as a High 
Performance Electrocatalyst for Oxygen Reduction Reaction. Int. J. Hydrogen Energy 2017, 42, 17504-17513.

(51) Bai, X.; Shi, Y.; Guo, J.; Gao, L.; Wang, K.; Du, Y.; Ma, T. Catalytic Activities Enhanced by Abundant Structural Defects and Balanced N Distribution of N-Doped Graphene in Oxygen Reduction Reaction. J. Power Sources 2016, 306, 85-91.

(52) Weththasinha, H. A. B. M. D.; Yan, Z.; Gao, L.; Li, Y.; Pan, D.; Zhang, M.; Lv, X.; Wei, W.; Xie, J. Nitrogen Doped Lotus Stem Carbon as Electrocatalyst Comparable to $\mathrm{Pt} / \mathrm{C}$ for Oxygen Reduction Reaction in Alkaline Media. Int. J. Hydrogen Energy 2017, 42, 2056020567.

(53) Liu, X.; Zhu, H.; Yang, X. One-Step Synthesis of DopamineDerived Micro/Mesoporous Nitrogen-Doped Carbon Materials for Highly Efficient Oxygen-Reduction Catalysts. J. Power Sources 2014, 262, 414-420.

(54) Miao, H.; Li, S.; Wang, Z.; Sun, S.; Kuang, M.; Liu, Z.; Yuan, J. Enhancing the Pyridinic N Content of Nitrogen-Doped Graphene and Improving Its Catalytic Activity for Oxygen Reduction Reaction. Int. J. Hydrogen Energy 2017, 42, 28298-28308.

(55) Bard, A. J.; Faulkner, L. R. Electrochemical Methods: Fundamentals and Applications, 2nd ed.; Wiley: New York, 2001.

(56) Davis, R. E.; Horvath, G. L.; Tobias, C. W. The Solubility and Diffusion Coefficient of Oxygen in Potassium Hydroxide Solutions. Electrochim. Acta 1967, 12, 287-297.

(57) Lide, D. R. CRC Handbook of Chemistry and Physics, 82nd ed.; CRC Press: Boca Ration, 2001.

(58) Wohlgemuth, S.-A.; White, R. J.; Willinger, M.-G.; Titirici, M.M.; Antonietti, M. A One-Pot Hydrothermal Synthesis of Sulfur and Nitrogen Doped Carbon Aerogels with Enhanced Electrocatalytic Activity in the Oxygen Reduction Reaction. Green Chem. 2012, 14, 1515.

(59) Dai, J.; Yuan, J.; Giannozzi, P. Gas Adsorption on Graphene Doped with B, N, Al, and S: A Theoretical Study. Appl. Phys. Lett. 2009, 95, 232105.

(60) Geng, D.; Chen, Y.; Chen, Y.; Li, Y.; Li, R.; Sun, X.; Ye, S.; Knights, S. High Oxygen-Reduction Activity and Durability of Nitrogen-Doped Graphene. Energy Environ. Sci. 2011, 4, 760-764.

(61) Wang, L.; Yang, C.; Dou, S.; Wang, S.; Zhang, J.; Gao, X.; Ma, J.; Yu, Y. Nitrogen-Doped Hierarchically Porous Carbon Networks: Synthesis and Applications in Lithium-Ion Battery, Sodium-Ion Battery and Zinc-Air Battery. Electrochim. Acta 2016, 219, 592-603.

(62) Pašti, I. A.; Gavrilov, N. M.; Dobrota, A. S.; Momčilović, M.; Stojmenović, M.; Topalov, A.; Stanković, D. M.; Babić, B.; CirićMarjanović, G.; Mentus, S. V. The Effects of a Low-Level Boron, Phosphorus, and Nitrogen Doping on the Oxygen Reduction Activity of Ordered Mesoporous Carbons. Electrocatalysis 2015, 6, 498-511.

(63) Zhang, T.; He, C.; Sun, F.; Ding, Y.; Wang, M.; Peng, L.; Wang, J.; Lin, Y. Co 3 O 4 Nanoparticles Anchored on Nitrogen-Doped Reduced Graphene Oxide as a Multifunctional Catalyst for $\mathrm{H} 2 \mathrm{O} 2$ Reduction, Oxygen Reduction and Evolution Reaction. Sci. Rep. 2017, 7, 43638. 